\title{
Federalismo fiscal e finanças públicas municipais potiguares: uma análise entre 2008/2014*
}

\author{
Fiscal federalism and potiguares municipal public finances: \\ an analysis in between 2008/2014
}

William Gledson e Silva, Francisco Danilo da Silva Ferreira e Rodrigo Farias**

\begin{abstract}
Resumo: Este artigo teve o objetivo de analisar, comparativamente, o impacto das diferentes fontes de receitas e gastos sobre o hiato de recursos municipais do Rio Grande do Norte (RN), no período 2008/2014. Metodologicamente, usou-se uma revisão de literatura acerca dos conceitos de federalismo fiscal e finanças municipais, além da mensuração dos resultados da pesquisa através do modelo de dados em painel estático. O artigo demonstrou que os anos 2008/2011 apontaram condições fiscais melhores, comparativamente ao período 2012/2014 em relação aos municípios potiguares, cuja crise de 2008, provavelmente, repercutiu sua força anos mais tarde e este contexto provocou, tendencialmente, a instabilidade política após 2014 no Brasil.
\end{abstract}

Palavras-chave: Municípios do RN. Hiato de Recursos. Período 2008/2014. Dados em Painel Estático. Federalismo Fiscal

\begin{abstract}
This paper had the objective to analyze comparatively the recipes and expenses origin different impact on the Rio Grande do Norte (RN) municipal resources gap in the period 2008/2014. Methodologically, it used a literature review about fiscal federalism and municipal finances concepts, besides the research results measurement through the static panel data model. The paper demonstrated that the years 2008/2011 pointed to better fiscal conditions, comparatively to the period 2012/2014 concerning the potiguares municipalities whose 2008 crisis, probably, reverberated your power years later and this context provoked, tendency, the political instability after 2014 in Brazil.
\end{abstract}

Keywords: RN Municipalities. Resource gap. Period 2008/2014. Static Panel Data. Fiscal Federalism

JEL: H77. H71. C33

\footnotetext{
* Submissão: 12/05/2020 | Aprovação: 27/09/2020 | DOI: 10.5380/re.v42i79.73682

** Respectivamente: (1) Professor Adjunto do Departamento de Economia da UERN/Campus Assú | ORCID: 0000-0003-0552-202X | E-mail: williangledson@gmail.com | (2) Professor Adjunto do Departamento de Economia da UERN/Campus Assú | ORCID: 0000-0001-8412-7540 | E-mail: ffdanilloferreira@gmail.com | (3) Graduando em Economia pela UERN | E-mail: rodfarias1@yahoo.com.br
} 


\section{Introdução}

No campo da economia do setor público, na verdade, torna-se importante resgatar elementos compatíveis ao denominado sistema político-administrativo, gravitando tal esfera de gestão entre perspectivas confederadas em um espectro e, diametralmente oposto, o chamado Estado unitário, situando características de uma autonomia relativa das unidades federativas diante do Governo Central, isto é, a liberdade das gestões subnacionais é limitada, apesar de existir, conforme discute Silva (2019).

O antes exposto, claramente, permite destacar que o sistema federativo está compreendido entre os cenários político-administrativos extremos enfatizados, atribuindo aos entes componentes a ocorrência de um pacto capaz de delimitar as competências de cada uma das instâncias governamentais, tanto em termos dos tributos a serem cobrados quanto às responsabilidades decorrentes da articulação constante na Federação, a partir de Mendes (2004).

De fato, Marques Junior et al. (2012) discutem o contexto federativo que se encere a política fiscal, quer dizer, os autores testam possibilidades via teoria dos jogos de quantas formas a relação da União, estados e municípios pode se reverberar, apontando haver nuances capazes de melhorar a eficiência na política fiscal através dos tributos recolhidos e/ou aplicação dos recursos na realização dos gastos públicos, nacionalmente e regionalmente.

Ferreira et al. (2019), por seu turno, identificam como federalismo fiscal o modo de relacionamento entre instâncias de governo, no terreno políticoadministrativo, acentuando ocorrer graus diferentes de autonomia fiscal das unidades subnacionais componentes da Federação, em outras palavras, o volume dos recursos arrecadados deve ser distribuído e o poder decisório no nível subnacional (estados e municípios especialmente) enfatizam o caráter de um sistema federativo.

Já Guedes e Gasparini (2007), via de regra, permitem compreender que descentralização fiscal corresponde a uma ampliação no volume das receitas governamentais distribuído mais contundentemente para os entes federativos subnacionais e um aumento no poder decisório das instâncias governamentais estaduais e municipais no Brasil, demonstrando o fortalecimento tendencial de amplitude subnacional. 
Outra constatação procede da leitura de Silva Filho et al. (2017), os quais asseveram que os municípios presentes na Federação brasileira, tomando como referência aqueles pertencentes aos estados baiano e pernambucano, viabilizam evidenciar quão os entes mencionados são capazes de revelar um padrão de arrecadação próprio fundamental para fortalecer as finanças públicas locais e, consequentemente, sublinhando as condições fiscais das diferentes instâncias governamentais analisadas empiricamente pela literatura.

Com efeito, Ferreira et al. (2017) sistematizam ocorrer uma metodologia importante para mensurar o comportamento fiscal de entes federativos estaduais e, por conseguinte, municipais, demonstrando que a diferença da Receita Corrente (RC) e a Despesa Corrente (DC), o denominado hiato de recursos permite medir a tendência de aumento ou queda do endividamento das diversas instâncias governamentais, sendo uma proxy relevante ao estudo em curso.

Nesse sentido, a pesquisa pretende se debruçar sobre as condições fiscais municipais do Rio Grande do Norte (RN), procurando medir o impacto de fontes de receitas e dispêndios diante do hiato de recursos, considerando os períodos de 2008/2011 e 2012/2014, os quais são corolários do corte temporal imediatamente pós-crise de 2008 e antes da instabilidade política instaurada no Brasil devido ao resultado das eleições presidenciais no final de 2014.

A hipótese do artigo, a rigor, procede da leitura de que o hiato de recursos municipal potiguar deve responder positivamente à influência das transferências intergovernamentais, particularmente aquelas originadas da União frente aos demais tipos de fontes de arrecadação auferidas pelos mencionados entes federativos; por outro lado, o hiato de recursos deve cair com o incremento dos gastos das esferas municipais, permitindo perceber que há indícios do corte 2012/2014 ser um fator explicativo para a instabilidade política a partir de 2015.

Os objetivos do trabalho, na verdade, pretendem examinar, comparativamente, o impacto das diferentes fontes de recursos arrecadados e os vários tipos de dispêndios sobre o hiato de recursos municipais potiguares, entre os anos de 2008/2014. Metodologicamente, o artigo admite a utilização do modelo de dados em painel estático para mensurar as condições fiscais das instâncias governamentais locais.

Finalmente, o estudo se encontra dividido em mais 4 seções além da introdução. Na sequência, são recuperados alguns fundamentos teóricos 
relevantes; a seguir, faz-se necessário descrever suscintamente os procedimentos metodológicos; posteriormente, os principais resultados devem ser discutidos, reservando para o término a apresentação de algumas considerações finais.

\section{Evidências acerca do federalismo fiscal e sua repercussão nas finanças municipais no Brasil}

Esta seção almeja discutir contribuições teóricas decorrentes da economia do setor público, sendo, mais especificamente, alguns conceitos relevantes como a ideia de federalismo e descentralização fiscais, os sobressaltos nas finanças públicas municipais provenientes das instabilidades macroeconômicas e os embates políticos capazes de impactar no movimento das receitas e despesas governamentais, independentemente da amplitude federativa, porém, a escala municipal é mais preocupante pela reduzida capacidade de arrecadação.

Assim, Musgrave (1959), teórico da primeira geração do federalismo fiscal, claramente, entende que os gastos públicos devem ser realizados, fundamentalmente, pela esfera governamental nacional, haja vista, provavelmente, a ocorrência de impactos negativos macroeconomicamente na Federação com a descentralização dos dispêndios aos níveis subnacionais.

Já Samuelson (1954), ainda que indo nessa mesma perspectiva, trata do denominado conceito de bem público puro, o qual significa haver na produção e oferta do enfatizado bem a não exclusão de qualquer consumidor em demandar tal provisão pública, além de que o incremento no número de consumidores do mencionado item não impactaria marginalmente nos benefícios auferidos pelos agentes indiscriminadamente (bem não rival).

Finalmente, Tiebout (1956) contesta convergência dos autores supracitados, em que os agentes localmente possuem uma cesta de preferências acerca dos serviços públicos, havendo a possibilidade de mobilidade entre as regiões de uma dada Federação, alocando de forma mais eficiente os recursos no financiamento dos dispêndios subnacionais, sendo uma prerrogativa bastante pertinente o fortalecimento dos entes federativos locais.

Após essas ressalvas precedentes, faz-se necessário recuperar nos estudos de Marques Junior et al. (2012) e Silva (2019) o significado do federalismo fiscal, ou seja, esse plano político-administrativo denota ocorrer relações de distribuição das competências e participação no volume do bolo tributário, cujo grau de tal presença 
se dá no nível da descentralização fiscal, a qual acentua quão mais ou menos autônomos são os entes subnacionais em uma Federação a exemplo da brasileira.

Guedes e Gasparini (2007) e Ferreira et al. (2019), por sua vez, apresentam a ideia de descentralização fiscal enquanto característica de mais elevada força institucional adquirida pelas instâncias governamentais regionais e locais no contexto federativo nacional, aumentando o poder decisório e a absorção de recursos via transferências intergovernamentais e/ou ampliação na competência de legislar no sentido de expandir a carga tributária, ampliar o número de funcionários públicos, etc.

Silva Filho et al. (2017) discutem o comportamento da arrecadação própria dos municípios baianos e pernambucanos, constatando ocorrer no plano federativo brasileiro um caráter de dependência fiscal representativo, quer dizer, o teste empírico realizado pelos autores é emblemático no sentido da percepção das características de descentralização beneficiadoras dos entes locais, gerando desafios macroeconômicos à União, compatibilizando com Musgrave (1959).

Seguindo o raciocínio, Paes e Siqueira (2008) testam um modelo de equilíbrio geral capaz de revelar uma distorção fiscal no sistema federativo brasileiro, sublinhando haver em uma eventual reforma tributária perdas para determinados entes subnacionais enquanto outros são favorecidos, cuja razão a tal cenário procede de um pacto federativo bastante inconsistente institucionalmente, sendo pertinente uma mudança nas relações sistêmicas, conforme críticas de Gomes e Mac Dowell (2000).

Os autores supracitados, a rigor, permitem admitir que o desenho de Federação brasileira requer ajustes institucionais no sentido de reduzir as distorções tributárias e a distribuição mais uniforme das competências, sublinhando ser fundamental um redimensionamento do pacto federativo, de acordo com a leitura de Bremaeker (2002), procurando adequar o padrão de gastos e os níveis de arrecadação.

Machado e Palotti (2015), via de regra, assinalam que o sistema federativo brasileiro proveniente da Constituição Federal (CF) de 1988 revela uma característica centralizadora em relação às políticas sociais, isto é, estados e municípios reproduzem as políticas da União em termos sociais, questionando a ideia de descentralização tão aceita na literatura. 
Contrariamente, trabalhos como os de Silva (2009) e Silva Filho et al. (2011), na verdade, mostram que as características federativas brasileiras desenham traços bastante descentralizados fiscalmente, cujas percepções empíricas asseveram nuances significativamente emblemáticas de uma força institucional decorrente da CF de 1988 no sentido da maior pujança municipal no plano da Federação do país.

Após esses esclarecimentos acerca do contexto federativo, faz-se necessário tecer algumas considerações sobre os aspectos políticos da Federação e, consequentemente, as possibilidades de instabilidade macroeconômica, cuja primeira percepção é proveniente do estudo de Gomes e Mac Dowell (2000), os quais assinalam que a partir da CF de 1988 ocorre um movimento de criação exacerbada de entes municipais economicamente pequenos e sustentados, fundamentalmente, pelas transferências intergovernamentais.

Uma questão de notável importância, a rigor, parte da leitura de Bachrach e Baratz (2011), onde os autores sublinham existir o denominado poder de agenda, isto é, dentro do contexto de um sistema federativo como o brasileiro, é factual perceber articulações dos grupos políticos em acrescentar na agenda interesses particulares predominantes aos interesses públicos, em outras palavras, há uma relação de forças para estabelecer políticas das diferentes naturezas em favor de agentes específicos.

Silva (2019), por seu turno, revela que dentro do próprio grupo dominante ocorre disputas significativas pelo engendramento de demandas, por exemplo, a classe empresarial atuante em distintos setores busca medidas econômicas peculiares, seja na via tributária, cambial, aplicação de dinheiro público na forma de investimentos, dentre outros, evidenciando um caráter bastante sintomático nas articulações políticas.

Assim, uma constatação derradeira nesta seção, categoricamente, procede das instabilidades macroeconômicas repousantes sobre as finanças públicas municipais em uma Federação, ou seja, Carvalho (2004) acentua que as turbulências internacionais capturadas pelo câmbio reverberam economicamente através dos sobressaltos no Saldo em Balanço de Pagamentos (SBP), necessitando de ajustes externos via taxas de juros para haver a recuperação da credibilidade mundialmente, especialmente em áreas emergentes como a América Latina. 
Em reforço ao antes exposto, Rocha (2009) argumenta que o resgate da credibilidade da economia brasileira decorre, fundamentalmente, da aceitação governamental do país acerca dos acordos com o Fundo Monetário Internacional (FMI), tornando a política discricionária com reduzido efeito anticíclico, principalmente após o advento da Lei de Responsabilidade Fiscal (LRF), cuja preocupação é conservar um volume representativo de superávit primário para financiar o serviço da dívida pública.

Afinal, Sakurai (2014) faz um teste econométrico via painel de dados, cujos resultados apontam a uma significativa tendência dos municípios brasileiros a responderem ao contexto macroeconômico desfavorável por meio de fatores econômicos dos próprios entes municipais, sendo pouco relevante o cenário político envolvido na análise, aspecto contrário ao vislumbrado no estudo de Gomes e Mac Dowell (2000) e convergente ao esperado nesta pesquisa.

\section{Procedimentos metodológicos}

O item agora inaugurado, claramente, pretende descrever de forma breve os procedimentos metodológicos essenciais ao desenvolvimento desta investigação, cujas ressalvas aqui evidenciadas suscitam nuances capazes de enfatizar aspectos que devem apontar resultados passíveis de atendimento do esperado no estudo, principalmente na combinação das tipologias de pesquisa, a saber: levantamento bibliográfico, documental, uso de amostragem e aplicação de modelagem quantitativa.

Nesse sentido, lança-se mão de uma revisão de literatura sobre os conceitos de federalismo e descentralização fiscais, consulta a documentos relativos aos resultados dos exercícios das finanças municipais potiguares junto à Secretaria do Tesouro Nacional (STN), mensurando as evidências do artigo através do modelo econométrico de dados em painel estático, repetindo procedimento de Sakurai (2014).

Com efeito, o período de análise prevê anos compreendidos entre o início da crise de 2008 em escala mundial e o corte imediatamente anterior ao momento da instabilidade política no Brasil, que tem seu advento após os resultados das eleições no final de 2014, contextualizando eventos históricos impactantes na economia do país, sendo importante medir tais cenários no campo fiscal de entes municipais, a exemplo do estado do RN, o qual é economicamente pobre. 
Assim, as variáveis do trabalho preconizam acentuar como aquela de natureza explicada atribuída ao hiato de recursos (diferença entre a RC e DC), respondendo ao conjunto de variáveis explicativas ligadas à Receita Tributária (RT), Imposto sobre Circulação de Mercadorias e Serviços (ICMS) e o Fundo de Participação dos Municípios (FPM) enquanto rubricas de arrecadação; já aquelas vinculadas aos gastos, sublinham-se as Despesas com Pessoal e Dispêndios Sociais (DS), cuja última reúne gastos com saúde, educação, habitação, assistência social, saneamento básico, conforme procedimento de Ferreira et al. (2017).

Nessas condições, torna-se cabível a realização do teste Breusch-Pagan (1980), o qual desenvolve um teste baseado no multiplicador de Lagrange para identificar se é pertinente fazer uso de análise de corte ou admitir um painel de dados, como na equação 1 a seguir postada:

$$
L M=\frac{n T}{2(T-1)}\left[\frac{\sum_{i=1}^{n}\left[\sum_{i=1}^{T} e_{i t}\right]^{2}}{\sum_{i=1}^{n} \sum_{i=1}^{T} e_{i t}^{2}}-1\right]^{2}
$$

Se a hipótese nula a ser verificada no teste de Breusch-Pagan não for rejeitada, via de regra, revela-se a necessidade da utilização do painel de dados em detrimento ao modelo de regressão procedente dos Mínimos Quadrados Ordinários (MQO).

Nesse sentido, Santolin et al. (2009) e Sakurai (2014) aplicam o modelo econométrico de dados em painel, o qual é conveniente a esta pesquisa devido ao fato de o objeto de estudo reunir corte transversal de dados e séries temporais, ou seja, a metodologia adequada para permitir a estimação de possíveis impactos das rubricas antes enfatizadas sobre o hiato de recursos procede do instrumental apontado e a seguir expresso:

$$
y_{i t}=\boldsymbol{X}_{i t} \boldsymbol{\beta}+\varepsilon_{i t} i=1,2, \ldots, i ; t=1,2, \ldots, t
$$

Na equação anteriormente explicitada, a rigor, os subíndices $i$ e $t$ refletem, respectivamente, as distinções entre as unidades observadas e o corte temporal que está sendo examinado; $y_{i t}$ significa a variável dependente para a unidade $i$ no período $t$; o vetor $\boldsymbol{X}_{\boldsymbol{i}}$ contém as variáveis explicativas, sendo esse $\boldsymbol{\beta}$ constituído 
pelos parâmetros a serem estimados e $\varepsilon_{i t}$ é o componente de erro estocástico para a unidade $i$ no período $t$.

Faz-se necessário acentuar que o painel de dados pode expressar um par de efeitos possíveis, os fixos e os aleatórios. $\mathrm{Na}$ modelagem de efeitos fixos o intercepto é específico para cada unidade, porém permanece constante ao longo do tempo; já os coeficientes angulares são análogos para todas as unidades. Dessa forma, a mencionada técnica pretende controlar os efeitos das variáveis omitidas do modelo que oscilam entre as unidades e que se preservam invariante durante o transcurso temporal, possibilitando ao intercepto capturar as diferenças comportamentais entre as observações, além das variáveis omitidas.

Os efeitos aleatórios, na verdade, conservam as mesmas proposições dos efeitos fixos, respectivamente, cuja diferença entre esses se refere ao tratamento do coeficiente linear, que no primeiro é tratado como variável aleatória, e não se relacionam com os regressores. Na especificação aleatória, a rigor, o coeficiente linear significa o valor médio de todos os interceptos individuais (de corte transversal) e os desvios são explicitados pelo aspecto de erro.

Santolin et al. (2009) sugerem o teste de Hausman para auxiliar na escolha entre o modelo de efeitos fixos ou aleatórios. Tal procedimento, na verdade, consiste nas distinções de estimativas das técnicas mencionadas, de modo que a hipótese nula supõe que os parâmetros estimados pela dupla de especificações não se diferenciam representativamente. Se a hipótese nula for rejeitada, via de regra, é preferível a adoção do modelo com efeitos fixos, atribuindo ao teste de Hausman ser apresentado como segue:

$$
H=\left[\hat{\beta}_{E F}-\hat{\beta}_{E A}\right]^{\prime}\left[V\left(\hat{\beta}_{E F}\right)-V\left(\hat{\beta}_{E A}\right)\right]^{-1}\left[\hat{\beta}_{E F}-\hat{\beta}_{E A}\right]
$$

Onde: $\hat{\beta}_{E F}$ é o vetor de estimativas de efeitos fixos e $\hat{\beta}_{E A}$ é o vetor de estimativas de efeitos aleatórios. O teste estatístico de Hausman possui distribuição assintótica $\chi 2$ (qui-quadrado) com graus de liberdade.

O último teste a ser realizado, na verdade, corresponde àquele que afere a denominada quebra estrutural, isto é, o teste Chow usado por Shikida et al. (2016) na análise de preço do boi gordo em São Paulo, sendo capaz de explicar as razões pelas quais se divide a série temporal desta pesquisa. 
Nessas circunstâncias, o estudo aqui postado e que almeja examinar o hiato de recursos municipal potiguar, tomando como referência o período de 2008/2014, requer os testes antes apontados para aferir o melhor modelo a ser considerado. Logo, o modelo empírico para a pesquisa em curso explicita:

$$
\begin{aligned}
\text { Hiato } & =\beta_{1}+\beta_{2} R T+\beta_{3} F P M+\beta_{4} I C M S+\beta_{5} \text { Despesap }+\beta_{6} \text { Despesas } \\
& +\varepsilon_{i t}
\end{aligned}
$$

Onde, Hiato é o hiato de recursos do município $i$ no instante $t$, a Receita Tributária da instância governamental i no transcurso temporal t, FPM corresponde a cota-parte do FPM do município $i$ no instante $t$, ICMS significa a cota-parte do ICMS municipal $i$ no período $t$, Despesap é a Despesa com Pessoal do ente subnacional $i$ no momento tDespesaso do município $i$ no instante $t$.

Portanto, os aspectos discutidos nesta seção preconizam meios relevantes ao alcance dos resultados esperados no artigo, resguardando ao prosseguimento do trabalho a análise das evidências obtidas por ocasião da utilização do instrumental de painel de dados estático, conforme apresentação postada no item subsequente.

\section{Apontamentos sobre finanças públicas municipais potiguares 2008/2014}

A seção atual, claramente, preconiza analisar e discutir os resultados deste estudo, o qual lança mão do exame do denominado hiato de recursos, o qual procura mensurar, como uma proxy, as condições fiscais dos municípios do Rio Grande do Norte, separando em um par de momentos as evidências entre os cortes temporais de 2008/2011 e 2012/2014. O procedimento prevê a tentativa de comparar uma série temporal logo após a crise de 2008 e, subsequentemente, anos antecedentes às instabilidades políticas instauradas no Brasil após as eleições no final de 2014.

Realiza-se, por seu turno, o teste Chow apontado no estudo de Shikida et al. (2016), em que a estatística $F$ da ordem de 6,52067 aqui obtida sublinha que se pode rejeitar a hipótese de ausência de quebra estrutural, ou seja, a separação nos cortes antes enfatizados revela pertinência estatística e robustez metodológica na análise do objeto. 
Assim, os aspectos empíricos aqui recuperados, via de regra, assinalam que a crise econômica eclodida em 2008 traz nuances de turbulências financeiras, cujo corolário destaca haver repercussões fiscais significativas sobre os entes federativos subnacionais brasileiros posteriores a tal evento, culminando em uma consequente instabilidade política anos mais tarde, não em uma evidente relação direta, mas com chances de ocorrer alguma ligação proveniente de prováveis administrações inadequadas no transcurso da reverberação do choque desfavorável mencionado previamente.

De fato, o teste de Breusch-Pagan (1980) permite que se rejeite a hipótese nula, sendo possível assumir uma análise em corte sem painel de dados, demonstrando, no entanto, a premente importância da utilização da metodologia aqui admitida e em conformidade com estudos empíricos, a exemplo de Santolin et al. (2009) e Sakurai (2014).

Seguindo o raciocínio, estima-se o teste empírico decorrente do instrumental de Hausman, o qual denota, categoricamente, que o estudo deve aceitar os efeitos fixos enquanto procedimentos mais adequados para a análise dos resultados da pesquisa, de acordo com trabalhos que encontram semelhantes contornos, segundo resgates de Ferreira e Silva (2017), quando esses discutem entes municipais nordestinos e do Norte brasileiros.

A partir dos resultados apresentados na Tabela 1, torna-se cabível apontar que o padrão de arrecadação municipal potiguar, categoricamente, entre os anos de 2008/2011 segue uma tendência compatível ao previsto pela literatura já revisitada anteriormente neste estudo, isto é, a cada 1,00 Real acrescentado na RT, FPM e ICMS o hiato de recursos melhora, respectivamente, em aproximadamente 0,16, 0,82 e 0,49 Centavos, convergindo aos achados por Silva Filho et al. (2011) para entes municipais de estados do Nordeste brasileiro.

Conquanto, o Fundo de Participação dos Municípios exerce a maior influência no sentido de melhorar as condições fiscais municipais potiguares manifestas no hiato de recursos, reservando à RT o menor impacto positivo, cuja explicação sustenta haver uma dependência bastante acentuada das instâncias governamentais locais norte-rio-grandenses quanto às transferências intergovernamentais, de acordo com a leitura de Silva (2009), sendo até mais relevante fiscalmente os repasses estaduais se comparado ao arrecadado de modo próprio. 
Já com relação aos dispêndios municipais potiguares, especialmente, o período selecionado de 2008/2011 assinala que o impacto da DP e DS, respectivamente, produz sobre o hiato de recursos uma piora da ordem de 0,66 e 0,02 Centavos aproximadamente diante da diferença RC e DC a cada 1,00 Real aumentado nas variáveis independentes antes apontadas, demonstrando serem os gastos com folha de funcionários o elemento mais significativo enquanto tipo de aplicação das receitas das instâncias observadas.

Tabela 1 - Painel de dados das condições fiscais municipais potiguares (2008-2011)

\begin{tabular}{|c|c|c|c|}
\hline Variáveis & Dados Agregados (MQO) & Efeitos Fixos & Efeitos Aleatórios \\
\hline \multirow[t]{2}{*}{ Constante } & $1,29625 * * *$ & $1,37319 * * *$ & $1,29071 * * *$ \\
\hline & $(4,307)$ & $(3,441)$ & $(4,347)$ \\
\hline \multirow[t]{2}{*}{ LN RT } & $0,181755^{* * *}$ & $0,163981 * * *$ & $0,178057 * * *$ \\
\hline & $(5,578)$ & $(3,757)$ & $(5,542)$ \\
\hline \multirow[t]{2}{*}{ LN FPM } & $0,869607 * * *$ & $0,822829 * * *$ & $0,860698 * * *$ \\
\hline & $(16,42)$ & $(12,14)$ & $(16,60)$ \\
\hline \multirow[t]{2}{*}{ LN ICMS } & $0,475564 * * *$ & $0,491305^{* * *}$ & $0,477437 * * *$ \\
\hline & $(10,70)$ & $(8,395)$ & $(10,94)$ \\
\hline \multirow[t]{2}{*}{ LN DP } & $-0,661348 * * *$ & $-0,662960 * * *$ & $-0,659078 * * *$ \\
\hline & $(-12,66)$ & $(-10,28)$ & $(-12,94)$ \\
\hline \multirow[t]{2}{*}{ LN DS } & $-0,0452030 *$ & $-0,0109876$ & $-0,0373853$ \\
\hline & $(1,73)$ & $(-0,3095)$ & $(-1,454)$ \\
\hline $\mathrm{R}^{2}$ & 0,93 & 0,82 & 0,81 \\
\hline Estatística F & 139,5259 & 396,2003 & 326,0215 \\
\hline $\begin{array}{l}\text { Número de } \\
\text { observações }\end{array}$ & 460 & 460 & 460 \\
\hline Hausman test & & 168,147 & 0,0001 \\
\hline $\begin{array}{l}\text { Teste de } \\
\text { Breusch-Pagan }\end{array}$ & & 30,748477 & 0,0000 \\
\hline
\end{tabular}

Ressalte-se, todavia, que apesar das características desafiadoras anteriormente expressas na literatura, é bastante sintomático admitir haver uma tendência a uma condição fiscal menos inadequada, pois a repercussão das rubricas sobre o hiato de recursos denota ocorrer influências maiores de fontes de arrecadação comparativamente ao quadro dos gastos, sendo possível sustentar nos 
anos do primeiro corte temporal haver indícios ao equilíbrio fiscal, segundo evidências empíricas de Silva Filho et al. (2017).

Torna-se cabível compreender, ao menos por extensão dos elementos cristalizados na literatura antes revisitada, de acordo com os trabalhos de Rocha (2009), Santolin et al. (2009) e Sakurai (2014), que a força institucional da Lei de Responsabilidade Fiscal tende a produzir a conservação de uma certa adequação dos gastos públicos aos limites financiáveis pelas receitas municipalmente no estado do Rio Grande do Norte, revelando ser importante perceber via instituições formais, conforme resgate de Silva (2009), a existência de um fator capaz de reproduzir desdobramentos positivos no terreno das finanças públicas.

Após os destaques acerca dos anos 2008/2011, particularmente, faz-se necessário expandir o escopo analítico ao triênio 2012/2014, o qual preconiza esmiuçar nuances envoltas ao declínio econômico no Brasil, provavelmente decorrente da crise de 2008 com seus sintomas sendo observados anos posteriores ao choque enfatizado, cujas reverberações fiscais devem ser cuidadosamente examinadas nos entes municipais potiguares.

A Tabela 2, por sua vez, revela que o aumento de 1,00 Real na RT, FPM e ICMS, respectivamente, proporciona incrementos no hiato de recursos municipal do RN da ordem de 0,06, 0,62 e 0,44 Centavos aproximadamente, sublinhando que as condições fiscais analisadas no período 2012/2014 conservam as características de dependência das transferências intergovernamentais, principalmente daquelas de origem Federal.

Seguindo o raciocínio, é pertinente enfatizar que o exame dos gastos traduz uma incompatível evidência no corte temporal de 2012/2014, pois o sinal da DP produz elevação do hiato de recursos, aspecto incongruente ao previsto na literatura empírica; já a DS expressa que na RC-DC há uma piora nas condições fiscais municipais em torno de 0,85 Centavos aproximadamente, asseverando que são os dispêndios sociais capazes de fazer reduzir o superávit das instâncias governamentais locais no triênio admitido. 
Tabela 2 - Painel de dados das condições fiscais municipais potiguares (2012-2014)

\begin{tabular}{|c|c|c|c|}
\hline Variáveis & Dados Agregados (MQO) & Efeito Fixo & Efeito Aleatório \\
\hline \multirow[t]{2}{*}{ Constante } & 1,283186 & 1,58532 & $-1,40442$ \\
\hline & $(1,31)$ & $(1,472)$ & $(-2,272)$ \\
\hline \multirow[t]{2}{*}{ LN RT } & 0,0465687 & 0,0624918 & 0,0642674 \\
\hline & $(0,772)$ & $(0,9207)$ & $(1,072)$ \\
\hline \multirow[t]{2}{*}{ LN FPM } & $0,594400 * * *$ & $0,619729 * * *$ & $0,603603 * * *$ \\
\hline & $(4,253)$ & $(3,743)$ & $(4,347)$ \\
\hline \multirow[t]{2}{*}{ LN ICMS } & $0,379874 * * *$ & $0,436062 * * *$ & $0,348655^{* * *}$ \\
\hline & $(3,443)$ & $(3,176)$ & $(3,206)$ \\
\hline \multirow[t]{2}{*}{ LN DP } & $-0,974310 * * *$ & $0,506572 * * *$ & $-1,28029 * * *$ \\
\hline & $(-4,025)$ & $(1,808)$ & $(-5,639)$ \\
\hline \multirow[t]{2}{*}{ LN DS } & $-1,04971 * * *$ & $-0,850624 * * *$ & $-1,10497 * * *$ \\
\hline & $(-8,245)$ & $(-4,434)$ & $(-8,567)$ \\
\hline $\mathrm{R}^{2}$ & 0,92 & 0,62 & 0,63 \\
\hline Estatística F & 30,25154 & 353,6222 & 427,6434 \\
\hline $\begin{array}{l}\text { Número de } \\
\text { observações }\end{array}$ & 370 & 370 & 370 \\
\hline Teste Hausman & & 28,5501 & 0,00000 \\
\hline $\begin{array}{l}\text { Teste de } \\
\text { Breusch-Pagan }\end{array}$ & & 35,717222 & 0,00000 \\
\hline
\end{tabular}

Fonte: Elaborado pelos autores com base em dados da FINBRA/STN (2019). $* * *$ significativo a $1 \%, * *$ significativo a $5 \%$ e $*$ significativo a $10 \%$.

Uma ressalva importante, por seu turno, é proveniente do sinal contrário apresentado pela DP, a qual impossibilita uma conclusão mais adequada sobre o impacto dos gastos com funcionalismo entre 2012/2014, sendo mais pertinente admitir, categoricamente, que os dados oficiais municipais potiguares no período são razoavelmente inconsistentes enquanto veracidade das informações fornecidas sobre os exercícios fiscais dos anos observados, porém não inviabilizando a análise aqui desenvolvida.

De fato, os resultados obtidos através do modelo de dados em painel utilizado em ambos os períodos, na verdade, demonstram que há uma flagrante piora nas condições fiscais municipais do Rio Grande do Norte no segundo momento analítico, cujo corolário permite destacar uma tendência de que a crise de 2008 é sustentada artificialmente pelas gestões federativamente praticadas 
Brasil afora e não sendo diferente nos municípios do RN, correspondendo a um provável fator de instabilidade política após as eleições gerais no final de 2014.

Afinal, os achados na pesquisa trazem nuances plausíveis no sentido de identificar, com significativas chances de ocorrência, que a situação econômica e financeira pelo menos municipalmente, a rigor, assinala haver bases agravadoras da oposição política quanto à gestão federativamente estabelecida no país, sendo o elemento contundente para os desdobramentos da crise política iniciada em 2015.

Portanto, apesar das constatações alcançadas e, igualmente, incompatibilidades no impacto da DP sobre o hiato de recursos no triênio 2012/2014, o que salta aos olhos procede da convergência dos resultados ao previsto na literatura empírica, asseverando ocorrer a aceitação da hipótese deste artigo, notadamente como tendência das relações fiscais aqui apresentadas e compatíveis aos fundamentos teóricos constantes no trabalho postado nestas páginas.

\section{Considerações finais}

Uma vez tendo desenvolvido este estudo, o qual trouxe como objetivo a preocupação em analisar, comparativamente, a influência de fontes de arrecadação e gastos municipais sobre o hiato de recursos, tomando como referência o período de 2008/2014, algumas explicitações foram relevantes e dignas de resgate nesta investigação.

Com efeito, os testes realizados mediante a aplicação do modelo de dados em painel, claramente, mostraram diferenças significativas quando se quebrou a série temporal considerada, na verdade, os primeiros anos examinados tiveram certa conservação de um eventual equilíbrio fiscal tendencial, enquanto no final do período houve evidências de queda na arrecadação e desajuste nos gastos.

Adicionalmente, observou-se que sobressaltos econômicos em escala mundial e/ou nacional produziram, provavelmente, piora fiscal decorrente da forte relação de dependência federativa, cuja perspectiva apontada revelou haver piora fiscal domesticamente após algum tempo depois da crise de 2008, onde os efeitos demoraram para se explicitar, acentuando graves repercussões anos mais tarde, lançando as bases favoráveis às instabilidades políticas.

Portanto, os resultados obtidos no estudo trouxeram nuances bastante sintomáticas da vulnerabilidade financeira presente nos municípios potiguares, cujas características de reduzido poder de arrecadação próprio, elevada 
necessidade das transferências governamentais, dedicação fiscal em financiar gastos com folha de funcionários, além da dificuldade econômica associada aos estilhaços do choque de 2008 ter sido um fator representativo ao desencadeamento da instabilidade política pós-eleições de 2014, tais elementos foram fundamentais a este contexto desolador, sendo plausível expandir o cenário do RN ao país como um interessante exemplo.

Finalmente, ao alcançar o término deste artigo, a rigor, importantes fatos demonstraram a pertinência da pesquisa, ainda que tantos aspectos não tenham sido admitidos. Os próximos trabalhos, por sua vez, poderiam assumir a ampliação da série temporal, comparação da situação entre estados nordestinos, aumentar o número de rubricas de arrecadação e dispêndios, bem como utilizar o método de painel dinâmico, tornando investigações semelhantes a essa mais robustas, consolidando a agora concluída.

\section{Referências}

BACHRACH, P.; BARATZ, M. S. Duas faces do poder. Revista de Sociologia e Política, v. 19, n. 40, p. 149-157, 2011.

BREMAEKER, F. Pacto federativo com justiça fiscal. Série Estudos Especiais, n. 38. Rio de Janeiro: Instituto Brasileiro de Administração Municipal, 2002.

BREUSCH, T.; PAGAN, A. The Lagrange multiplier test and its applications to model specification in econometrics. The Review of Economic Studies, v. 47, n. 1, p. 239-253, 1980.

CARVALHO, C. Crises cambiais, finanças públicas e estabilidade financeira na América Latina: algumas lições da experiência recente. Textos para discussão da PUC-SP, 2004.

FERREIRA, F.; SILVA, W.; LIMA, F. Ajuste fiscal estadual brasileiro: uma análise no período 1995/2016. Revista Espacios, v. 38, n. 39, p. 2-12, 2017.

FERREIRA, F.; SILVA, W.; SOUZA, J. Preços macroeconômicos (câmbio e inflação) e o Fundo de Participação dos Municípios (FPM) no Brasil: uma análise para o período 2011-2018. Revista Documento e Monumento, v. 27, n.1, p. 159$182,2019$.

FERREIRA, F.; SILVA, W. Comportamento da receita corrente líquida per capita dos municípios do Norte e Nordeste do Brasil no período de 2002 a 2011: uma 
análise em dados em painel. Revista de Administração e Negócios da Amazônia, v. 9, p. 10-25, 2017.

GUEDES, K.; GASPARINI, C. Descentralização fiscal e tamanho do Governo no Brasil. Economia Aplicada, v. 11, n. 2, p. 303-327, 2007.

GOMES, G.; MAC DOWELL, M. Descentralização política, federalismo fiscal e criação de municípios: o que é mau para o econômico nem sempre é bom para o social. Texto para Discussão n. 0706. Brasília: IPEA, 2000.

MACHADO, J.; PALOTTI, P. Entre cooperação e centralização: federalismo e políticas sociais no Brasil pós-1988. Revista Brasileira de Ciências Sociais, v. 30, n. 88, p. $61-82,2015$.

MARQUES JUNIOR, L.; OLIVEIRA, C.; LAGEMANN, E. A política fiscal como um jogo entre União, estados e municípios no federalismo fiscal brasileiro. Economic Analyses of Law Review, v. 3, n. 2, p. 207-227, 2012.

MENDES, M. Federalismo fiscal. IN: ARVATE, P.; BIDERMAN, C. (Orgs.). Economia do setor público no Brasil. Rio de Janeiro: Elsevier, 2004.

MUSGRAVE, R. The theory of public finance. Nova Iorque: McGraw-Hill, 1959.

PAES, N.; SIQUEIRA, M. Desenvolvimento regional e federalismo fiscal no Brasil: em busca da igualdade na distribuição de receitas. Economia Aplicada, v. 12, n. 4, p. 707-742, 2008.

ROCHA, F. Política fiscal através do ciclo e operação dos estabilizadores fiscais. EconomiA, v. 10, n. 3, p. 483-499, 2009.

SAKURAI, S. Superávit e déficit fiscal dos municípios brasileiros: uma aplicação do modelo de viés de seleção em painel. Nova Economia, v. 24, n. 3, p. 517-540, 2014.

SAMUELSON, P. The pure theory of public expenditure. Review of Economics and Statistics, v. 36, n. 4, p. 387-389, 1954.

SANTOLIN, R.; JAYME JUNIOR, F.; REIS, J. Lei de Responsabilidade Fiscal e implicações na despesa de pessoal e de investimento nos municípios mineiros: um estudo com dados em painel dinâmico. Estudos Econômicos, v. 39, n. 4, p. 895923, 2009.

SILVA FILHO, L. A.; LIMA, F.; PALÁCIO, J.; SILVA, W. Comportamento das receitas próprias municipais da Bahia e de Pernambuco: análise do primeiro 
decênio do século XXI. Revista de Economia Mackenzie, v. 14, n. 1, p. 107-122, 2017.

SILVA FILHO, L.; LIMA E SILVA, Y.; FREITAS E SILVA, A.; SILVA, W. Considerações sobre receitas municipais em estados do Nordeste: comparação entre Bahia, Ceará e Piauí 2007. Revista Econômica do Nordeste, v. 42, n. 2, p. 409-424, 2011.

SILVA, W. Autonomia relativa e descentralização físcal: uma análise da arrecadação estadual do Rio Grande do Norte. Revista Paranaense de Desenvolvimento, v. 40, n. 136, p. 65-78, 2019.

SILVA, W. Finanças públicas na nova ordem constitucional brasileira: uma análise comportamental dos municípios potiguares nos anos antecedentes e posteriores a Lei de Responsabilidade Fiscal (LRF). Dissertação (Mestrado) - Programa de PósGraduação em Economia, Universidade Federal do Rio Grande do Norte, Natal, 2009.

SHIKIDA, C.; PAIVA, G.; ARAUJO JUNIOR, A. Análises de quebras estruturais na série do preço do boi gordo no estado de São Paulo. Economia Aplicada, v. 20, n. 2, p. 265-286, 2016.

TIEBOUT, C. A pure theory of local expenditures. Journal of Political Economy, v. 64, n. 5, p. 416-424, 1956. 